\title{
The Response of Precipitation Minus Evapotranspiration to Climate Warming: Why the "Wet-Get-Wetter, Dry-Get-Drier" Scaling Does Not Hold over Land*
}

\author{
MICHAEL P. BYRNE \\ ETH Zürich, Zürich, Switzerland \\ PAUl A. O'GORMAN \\ Massachusetts Institute of Technology, Cambridge, Massachusetts
}

(Manuscript received 22 May 2015, in final form 26 July 2015)

\begin{abstract}
Simulations with climate models show a land-ocean contrast in the response of $P-E$ (precipitation minus evaporation or evapotranspiration) to global warming, with larger changes over ocean than over land. The changes over ocean broadly follow a simple thermodynamic scaling of the atmospheric moisture convergence: the so-called "wet-get-wetter, dry-get-drier" mechanism. Over land, however, the simple scaling fails to give any regions with decreases in $P-E$, and it overestimates increases in $P-E$ compared to the simulations. Changes in circulation cause deviations from the simple scaling, but they are not sufficient to explain this systematic moist bias. It is shown here that horizontal gradients of changes in temperature and fractional changes in relative humidity, not accounted for in the simple scaling, are important over land and highlatitude oceans. An extended scaling that incorporates these gradients is shown to better capture the response of $P-E$ over land, including a smaller increase in global-mean runoff and several regions with decreases in $P-E$. In the zonal mean over land, the gradient terms lead to a robust drying tendency at almost all latitudes. This drying tendency is shown to relate, in part, to the polar amplification of warming in the Northern Hemisphere, and to the amplified warming over continental interiors and on the eastern side of midlatitude continents.
\end{abstract}

\section{Introduction}

Earth's water cycle is expected to change substantially as the climate warms (Collins et al. 2013), impacting societies, economies, and ecosystems throughout the world (IPCC 2014). The net water flux into the surfacethe precipitation minus evaporation over ocean or precipitation minus evapotranspiration over land $(P-E)-$ is a key aspect of the water cycle. Over oceans $P-E$ strongly affects the salinity of the mixed layer, while over continents it determines the sum of surface and subsurface runoff. In the long-term mean and averaged

\footnotetext{
* Supplemental information related to this paper is available at the Journals Online website: http://dx.doi.org/10.1175/JCLI-D-15-0369.s1.

Corresponding author address: Michael P. Byrne, ETH Zürich, Sonneggstrasse 5, 8092 Zürich, Switzerland.

E-mail: michael.byrne@erdw.ethz.ch
}

globally, $P-E$ over land must approximately balance $P-E$ over ocean, but the greater surface water availability over ocean implies that $P-E$ behaves differently locally over ocean compared to land in the current climate, and differences in the response to climate change may also be expected. Climate-model simulations of warming climates exhibit a land-ocean contrast in the responses of both $P-E$ and precipitation (Roderick et al. 2014; Vallis et al. 2015), with generally smaller magnitude changes over land than ocean.

Over ocean, simulated changes in $P-E$ on large scales are found to scale with changes in surface temperature (Mitchell et al. 1987; Chou and Neelin 2004; Held and Soden 2006; Chou et al. 2009). A simple thermodynamic scaling yields a moistening of the tropics and extratropics and a drying of the subtropics at a rate of approximately $7 \% \mathrm{~K}^{-1}$ with respect to the local surface temperature change (Held and Soden 2006). This "wet-get-wetter, dry-get-drier" response is a consequence of increasing atmospheric water vapor content and transport in a 
warming climate, following the Clausius-Clapeyron relation at roughly constant relative humidity [a similar mechanism was termed the direct moisture effect by Chou and Neelin (2004)]. The dynamical contribution to precipitation changes is also important locally (Xie et al. 2010; Huang et al. 2013; Chadwick et al. 2013), but the simple thermodynamic scaling captures the planetaryscale pattern of $P-E$ changes in climate-model simulations (Held and Soden 2006). The resulting amplification of the spatial pattern of $P-E$ over ocean is consistent with observed salinity changes over recent decades, although the rate of amplification inferred from observed salinity changes is higher than what most climate models simulate (Durack et al. 2012).

In the time mean over land, $P-E$ is generally positive or close to zero because evapotranspiration cannot exceed precipitation in the time mean when averaged over a drainage basin. As a result, the simple thermodynamic scaling implies that $P-E$ over land should either increase or stay close to zero as the climate warms. One implication is an increase in global-mean runoff as the climate warms. The observed trend in global continental discharge from rivers is negative but not statistically significant (Dai et al. 2009). Global-mean runoff does increase with warming in simulations of twenty-first-century climate change (Alkama et al. 2013), although we show here that it does not increase as much as the simple scaling implies. Importantly, the simple scaling does not imply that drylands should get drier with climate warming, even though this is sometimes assumed to be the case.

The physical basis of the simple scaling is weaker over land than ocean (Held and Soden 2006), and recent studies have found that it fails to capture simulated changes in $P-E$ over land (Roderick et al. 2014) and is not confirmed by historical observations over land (Greve et al. 2014). As we will show, simulations of global warming exhibit only weak increases in $P-E$ over land, at a rate substantially smaller than the $7 \% \mathrm{~K}^{-1}$ given by the simple scaling. Furthermore, projected regional decreases in $P-E$ (Seager and Vecchi 2010), for instance in the Mediterranean (Seager et al. 2014a), cannot be explained by the "wet-get-wetter" mechanism. Deviations from the simple scaling can occur over both ocean and land because of changes in the mean circulation and eddies (e.g., Seager et al. 2010; Scheff and Frierson 2012; Huang et al. 2013; Seager et al. 2014a,b). In addition, changes in horizontal temperature gradients, which are neglected by the simple scaling, are important for changes in $P-E$ between the present and the Last Glacial Maximum (LGM) over both land and ocean (Boos 2012). However, given that the simple scaling performs systematically worse over land than ocean in simulations of global warming (Roderick et al.
2014), it seems that there may be a robust and widespread mechanism retarding the response of the terrestrial water cycle to global warming.

Here, we investigate the physical mechanisms controlling projected changes in $P-E$ over all land regions in simulations from phase 5 of the Coupled Model Intercomparison Project (CMIP5). Both temperature and relative humidity respond differently over land than ocean (e.g., Byrne and O'Gorman 2013b), and we show here that the response of $P-E$ is affected by these differences. A sensitivity of tropical precipitation to changes in relative humidity over land has already been proposed (Chadwick et al. 2013), but here we find it is gradients in fractional changes in relative humidity rather than local changes in relative humidity that are important for changes in $P-E$. We will use the term "drying" to refer to a decrease in $P-E$ over land, but we recognize that a drying influence can be measured in other ways. For example, some recent studies have found widespread decreases in the ratio of precipitation to potential evapotranspiration (the aridity index) in simulations of a warming climate (Fu and Feng 2014; Scheff and Frierson 2015). Our focus is on changes in $P-E$ that may be expected to affect runoff, soil moisture, and groundwater.

We begin by describing the changes in $P-E$ in global warming simulations and demonstrating that the simple scaling does not capture the response over land (section 2 ). We then introduce an extended scaling that better captures the changes in $P-E$ over land (section 3$)$. The extended scaling accounts for changes in horizontal temperature gradients [in a similar way to an expression used by Boos (2012)], and it also accounts for gradients in the fractional change in relative humidity. We discuss the physical mechanisms that lead to a drying tendency over land relative to the simple scaling (section 4) and the role of dynamical changes in the land response (section 5), before we summarize our results and their implications (section 6).

\section{2. $P-E$ changes in CMIP5 simulations and the simple scaling}

We analyze simulated changes in $P-E$ from 10 CMIP5 models. ${ }^{1}$ The climate change we consider is the difference between 30-yr time averages in the historical (1976-2005; referred to as the base climate) and the

\footnotetext{
${ }^{1}$ The models used are BCC-CSM1.1, BCC-CSM1.1-M, BNU-ESM, CNRM-CM5, IPSL-CM5A-LR, MIROC5, MIROC-ESM, MIROCESM-CHEM, MRI-CGCM3, MRI-ESM1 (expansions of acronyms are available online at http://www.ametsoc.org/PubsAcronymList). Other models were excluded because the necessary data were not available at the time when the analysis was conducted.
} 

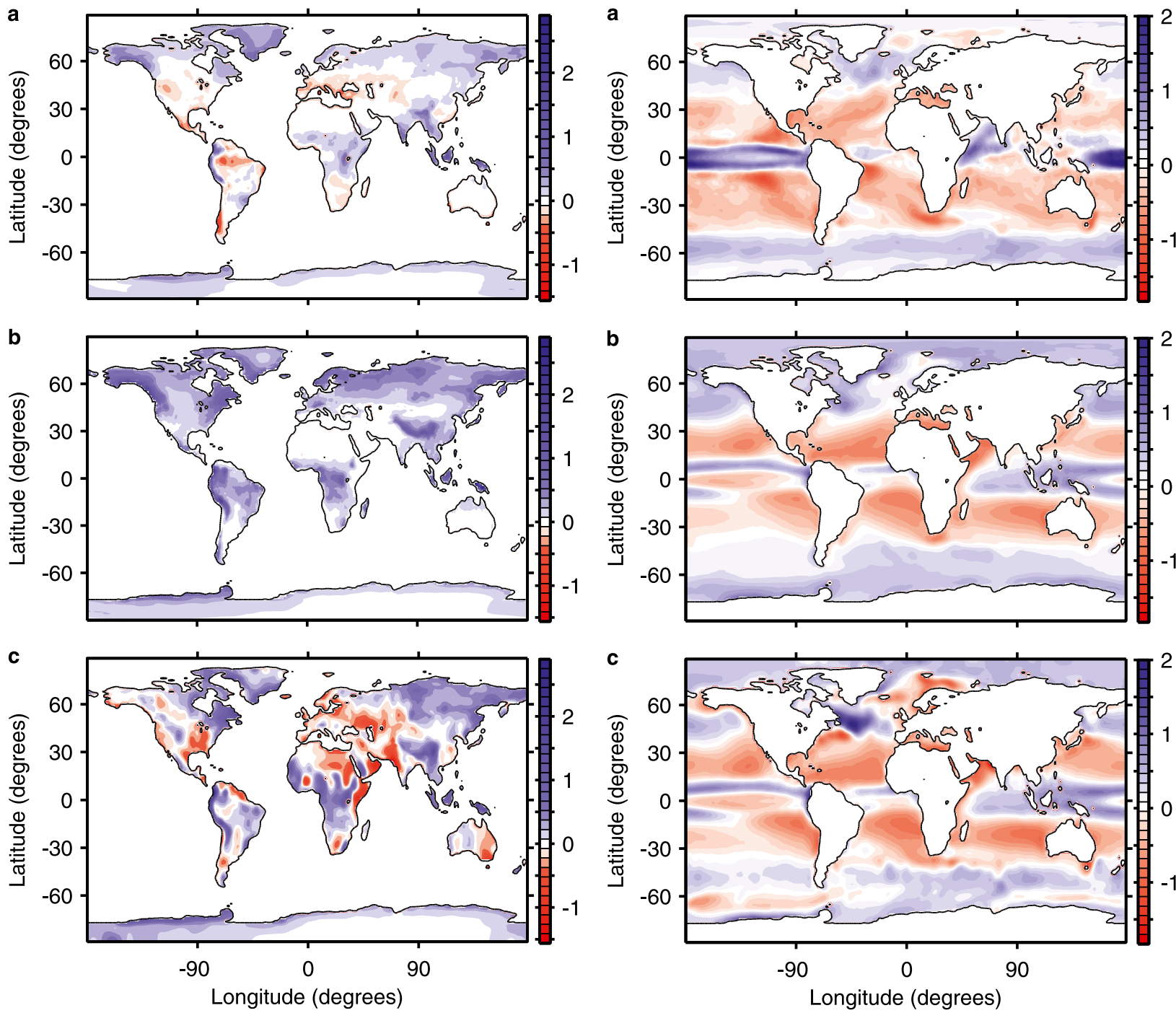

FIG. 1. Multimodel-mean changes in (a) $P-E\left(\mathrm{~mm} \mathrm{day}^{-1}\right)$ between the historical (1976-2005) and RCP8.5 (2070-99) simulations along with the estimated changes from (b) the simple scaling $[(2)]$ and (c) the extended scaling [(7)]. Only the changes over land are shown. The results for each model are linearly interpolated to a common grid prior to calculation of the multimodel mean. For (c), the gradient terms in the extended scaling have been smoothed to reduce noise using three passes of a $3 \times 3$-point Gaussian filter with a standard deviation of 0.75 grid points.

RCP8.5 (2070-99) simulations. For each simulation, we use the r1i1p1 ensemble member (Taylor et al. 2012). Monthly-mean precipitation and evaporation are used to evaluate $P-E$ in each climate and to evaluate the simple and extended scalings discussed later. Monthlymean surface-air temperature and relative humidity are also needed to evaluate the scalings, and daily-mean winds and specific humidity are used to calculate the vertically integrated horizontal moisture flux that is needed for the extended scaling.

FIG. 2. As in Fig. 1, but showing only ocean regions.

The simulations show a $P-E$ response with substantial spatial structure (Figs. 1a and 2a). Over oceans, the "wet-get-wetter, dry-get-drier" pattern is evident, with moistening in the tropics and extratropics and drying in the subtropics as the climate warms (Fig. 2a). This pattern is strongly evident in the zonal mean (Fig. 3a), in agreement with the earlier CMIP3 simulations (e.g., Held and Soden 2006). $P-E$ in the base climate has a smaller magnitude over land than over ocean in many regions (Fig. S1; supplementary material is available online at http://dx.doi.org/10.1175/JCLI-D15-0369.s1), and the absolute changes in $P-E$ over land (Figs. 1a and 3b) are also mostly weaker than over ocean (Figs. 2a and 3a). In the zonal mean over land, there is projected moistening in the tropics and Northern Hemisphere extratropics, negligible changes in the 

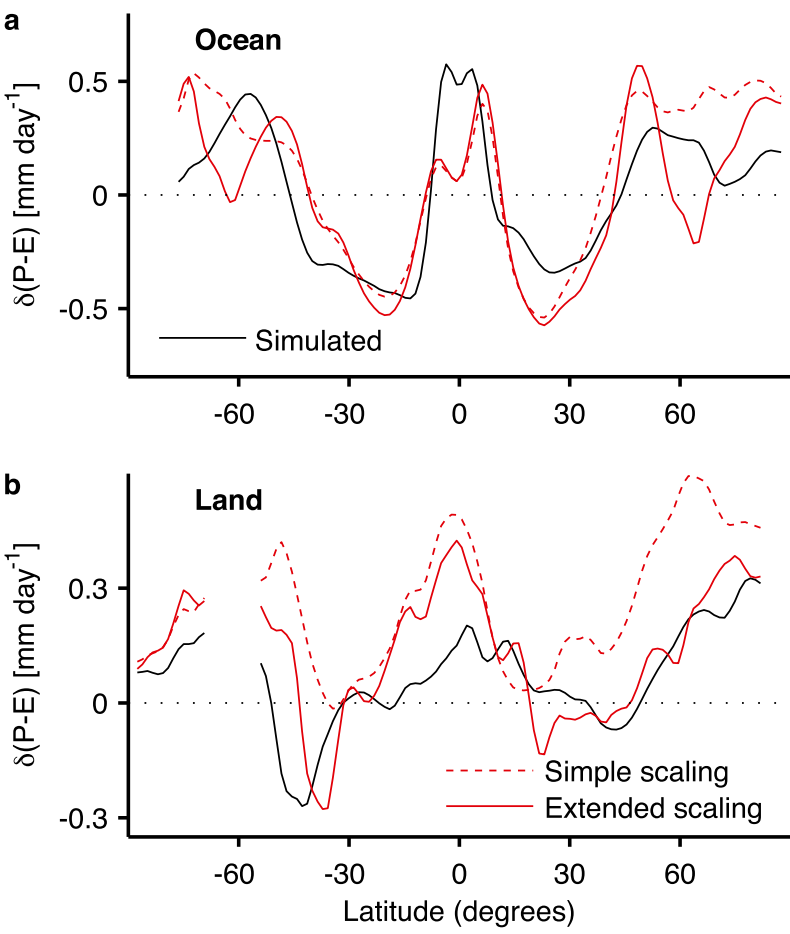

FIG. 3. Multimodel-mean changes in zonal-mean $P-E$ over (a) oceans and (b) land. Black lines show the simulated changes. Red dashed lines and red solid lines are the estimates from the simple [(2)] and extended scalings [(7)], respectively. Each curve has been smoothed in latitude to reduce noise using a three-point moving-average filter, and this smoothing is also applied to the subsequent zonal-mean plots.

subtropics, and drying in the Southern Hemisphere midlatitudes (Fig. 3b).

In statistical steady state, $P-E$ is balanced by moisture convergence in the atmosphere, $P-E=-\nabla \cdot \mathbf{F}$, where $\mathbf{F}$ is the horizontal moisture flux integrated vertically through the depth of the atmosphere, and all quantities are averaged in time. Changes in $P-E$ as the climate warms are balanced by the convergence of changes in the moisture flux $\mathbf{F}$,

$$
\delta(P-E)=-\nabla \cdot \delta \mathbf{F},
$$

where $\delta$ refers to the change between two climates. The changes in $\mathbf{F}$ are associated with changes in the specific humidity field and the atmospheric circulation. By neglecting the effect of climate change on the atmospheric circulation, relative humidity, and horizontal temperature gradients, and by assuming that the vertically integrated horizontal moisture flux scales with the lowertropospheric moisture content, Held and Soden (2006) used the perturbation moisture budget [(1)] to derive the following simple scaling for the change in $P-E$ between two climates:

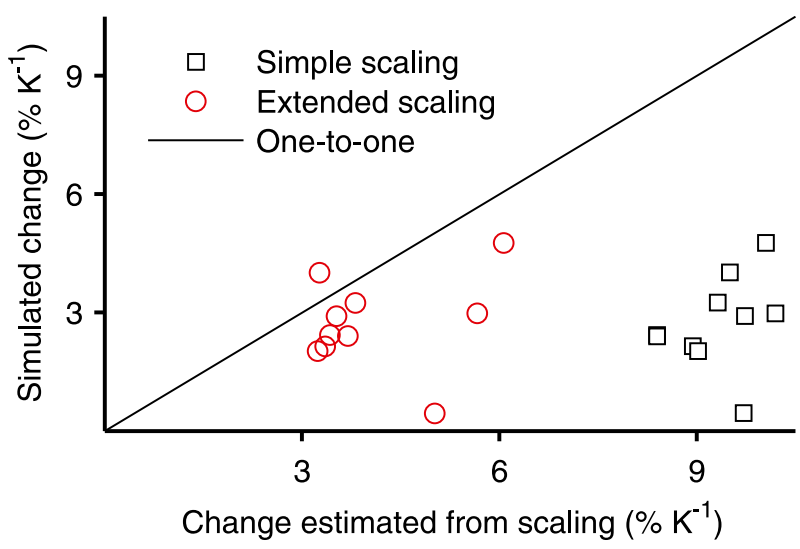

FIG. 4. Simulated changes in global-mean land $P-E$ (i.e., changes in global-mean runoff) vs the estimates from the simple scaling (black squares) and the extended scaling (red circles). The simulated and estimated changes have been expressed as a percentage of their base-climate values and normalized by the global-mean changes in surface-air temperature. The black line is the one-to-one line.

$$
\delta(P-E) \approx \alpha \delta T_{s}(P-E),
$$

where $\alpha$ is a temperature-dependent parameter derived from the Clausius-Clapeyron relation, $\delta T_{s}$ is the change in the time-mean local surface-air temperature, and $P-E$ on the right-hand side of the scaling is evaluated in the base climate. The parameter $\alpha$ was specified by Held and Soden to be $7 \% \mathrm{~K}^{-1}$, but we calculate $\alpha$ at each latitude and longitude and for each climatological month using $\alpha=L /\left(R_{v} T_{s}^{2}\right)$ where $L$ is the latent heat of vaporization and $R_{v}$ is the gas constant for water vapor. Under global warming, this simple scaling suggests an enhancement of the climatological water cycle $(P-E)$ at a rate of approximately $7 \% \mathrm{~K}^{-1}$.

The simple scaling (and later the extended scaling) is applied to estimate the $P-E$ changes between the historical and RCP8.5 simulations at each model grid point and for each calendar month individually before taking the annual mean (and, in some figures, the zonal means over land or ocean). Despite its simplicity and neglect of changes in circulation, the simple scaling captures much of the simulated response over oceans (Figs. 2b and 3a). The simple scaling is much less successful over land (Figs. $1 \mathrm{~b}$ and $3 \mathrm{~b}$ ). It implies that almost all land should become wetter as the climate warms (because climatological $P-E \geq 0$ over land on large scales), but there are many land regions with decreases in $P-E$ in the simulations. Where $P-E$ does increase over land, such as in the Northern Hemisphere high latitudes, the simple scaling overestimates the response. The global-mean increase over land is also overestimated (Fig. 4) by about a factor of 5 in the 
multimodel mean and by as much as a factor of 21 in one model.

In the next section, we derive an extended scaling for changes in $P-E$ and show that spatial heterogeneity in both changes in temperature and fractional changes in relative humidity must be taken into account over land.

\section{Extended scaling for $P-E$}

As the climate warms, strong land-ocean contrasts in the near-surface temperature and relative humidity responses are expected. There is larger warming over land (Sutton et al. 2007; Joshi et al. 2008; Byrne and O'Gorman 2013a,b), and relative humidity increases over ocean but decreases over land (O'Gorman and Muller 2010; Laîné et al. 2014). Land-ocean contrasts, along with other robust features of global warming simulations such as polar amplification (e.g., Holland and Bitz 2003), affect the spatial pattern of lowertropospheric specific humidity changes and consequently influence the atmospheric moisture budget and the $P-E$ response. However, the simple scaling [(2)] accounts only for local changes in specific humidity (at fixed relative humidity), neglecting changes in horizontal specific humidity gradients. The simple scaling is also unlikely to be able to represent the effect on $P-E$ from decreases in stomatal conductance due to increases in atmospheric $\mathrm{CO}_{2}$ concentrations, even though these decreases have been found to contribute to the changes in both surface-air relative humidity and $P-E$ over land (Cao et al. 2010).

\section{a. Derivation of extended scaling}

We derive an extended scaling for the $P-E$ response that takes account of changes in relative humidity and horizontal temperature gradients (although it still neglects changes in the circulation). First, we decompose the vertically integrated horizontal moisture flux into components associated with the monthly-mean circulation and with transient eddies, $\mathbf{F}_{\text {mean }}$ and $\mathbf{F}_{\text {eddy }}$, respectively. Neglecting changes in circulation, we assume that the flux associated with the monthly-mean circulation scales with the near-surface specific humidity, $\delta \mathbf{F}_{\text {mean }} \approx\left(\delta q_{s} / q_{s}\right) \mathbf{F}_{\text {mean }}$, where $q_{s}$ is the surface-air specific humidity. Substituting this into the perturbation moisture budget (1), we obtain

$$
\delta(P-E)_{\text {mean }} \approx\left(\delta q_{s} / q_{s}\right)(P-E)_{\text {mean }}-\mathbf{F}_{\text {mean }} \cdot \nabla\left(\delta q_{s} / q_{s}\right),
$$

where $(P-E)_{\text {mean }}=-\nabla \cdot \mathbf{F}_{\text {mean }}$ is the component of climatological $P-E$ associated with the monthly-mean circulation.
The moisture flux by transient eddies is approximately diffusive for short velocity correlation times (O'Gorman and Schneider 2006). We assume that transient eddies transport moisture diffusively down the mean surface-air specific humidity gradient, such that $\mathbf{F}_{\text {eddy }} \approx-\nabla q_{s}$ where $\mathscr{O}$ is the diffusivity. We can then approximate the transient-eddy component $(P-E)_{\text {eddy }}=-\nabla \cdot \mathbf{F}_{\text {eddy }}$ as

$$
(P-E)_{\mathrm{eddy}} \approx \nabla \cdot \mathscr{\nabla} q_{s} .
$$

To find a form of the scaling for the eddy component that is similar to that of the mean component, it is useful to write $\delta(P-E)_{\text {eddy }} \approx \nabla \cdot \vartheta\left[\left(\delta q_{s} / q_{s}\right) q_{s}\right]$, where we have neglected the effect of climate change on the diffusivity. Applying the product rule to the right-hand side of this expression, the scaling for the transient eddy component of $P-E$ changes may be written as

$$
\delta(P-E)_{\mathrm{eddy}} \approx\left(\delta q_{s} / q_{s}\right)(P-E)_{\mathrm{eddy}}-2 \mathbf{F}_{\mathrm{eddy}} \cdot \nabla\left(\delta q_{s} / q_{s}\right),
$$

where we have further neglected the gradient of the diffusivity and the Laplacian of fractional specific humidity changes. ${ }^{2}$ Adding (3) to (5), a scaling for $P-E$ in terms of fractional changes in specific humidity is obtained:

$$
\delta(P-E) \approx\left(\delta q_{s} / q_{s}\right)(P-E)-\mathbf{G} \cdot \nabla\left(\delta q_{s} / q_{s}\right),
$$

where $\mathbf{G}=\mathbf{F}+\mathbf{F}_{\text {eddy }}=\mathbf{F}_{\text {mean }}+2 \mathbf{F}_{\text {eddy }}$. Note that the modified moisture flux $\mathbf{G}$ includes double the contribution from the eddy component when compared to the moisture flux $\mathbf{F}$.

To facilitate a straightforward comparison with the simple scaling [(2)], we relate the fractional change in specific humidity to changes in temperature and relative humidity. We approximate the relative humidity as the ratio of the specific humidity to the saturation specific humidity, such that $\delta q_{s} / q_{s} \approx \delta q_{s}^{*} / q_{s}^{*}+\delta H_{s} / H_{s}$, where $q_{s}^{*}$ is the surface-air saturation specific humidity and $H_{s}$ is the surface-air relative humidity. Further relating the changes in surface saturation

\footnotetext{
${ }^{2}$ Scale analysis suggests that the Laplacian term $\left[q_{s} \nabla^{2}\left(\delta q_{s} / q_{s}\right)\right]$ omitted in the derivation of (5) is smaller than the retained terms $\left[\left(\delta q_{s} / q_{s}\right)(P-E)_{\text {eddy }}\right]$ and $\left[-2 \mathbf{F}_{\text {eddy }} \cdot \nabla\left(\delta q_{s} / q_{s}\right)\right]$ to the extent that the length scale of variation of $\left(\delta q_{s} / q_{s}\right)$ is larger than that of $q_{s}$. In addition, the Laplacian term is noisy and difficult to calculate reliably because of the need to estimate second-order derivatives and the eddy diffusivity. For these reasons we have not retained the Laplacian term in our derivation, even though it may make a nonnegligible contribution particularly on small scales.
} 
specific humidity to the changes in surface temperature by $\delta q_{s}^{*} / q_{s}^{*} \approx \alpha \delta T_{s}$, where we calculate $\alpha$ locally using $\alpha=L /\left(R_{v} T_{s}^{2}\right)$, we obtain an extended scaling for $P-E$ :

$$
\delta(P-E) \approx \underbrace{\alpha \delta T_{s}(P-E)}_{\text {simple scaling }}+\underbrace{\left(\delta H_{s} / H_{s}\right)(P-E)-\mathbf{G} \cdot \nabla\left(\alpha \delta T_{s}\right)-\mathbf{G} \cdot \nabla\left(\delta H_{s} / H_{s}\right)}_{\text {additional terms }} .
$$

If changes in relative humidity and gradients of $\alpha \delta T_{s}$ are neglected, the simple scaling [(2)] is recovered. The extended scaling has three additional terms compared to the simple scaling: a term related to local relative humidity changes $\left[\left(\delta H_{s} / H_{s}\right)(P-E)\right]$, a term primarily related to gradients of changes in temperature $\left[-\mathbf{G} \cdot \nabla\left(\alpha \delta T_{s}\right)\right]$, and a term related to gradients of fractional changes in relative humidity $\left[-\mathbf{G} \cdot \nabla\left(\delta H_{s} / H_{s}\right)\right]$. To simplify the discussion, we will often refer to gradients of changes in temperature rather than gradients of $\alpha \delta T_{s}$, but the gradients of $\alpha$ are retained for greater accuracy. Boos (2012) considered the term $-\alpha \mathbf{F} \cdot \nabla \delta T_{s}$ [similar to $-\mathbf{G} \cdot \nabla\left(\alpha \delta T_{s}\right)$ in the extended scaling] and found it to be important for changes in $P-E$ between the present day and the LGM. ${ }^{3}$

Although the extended scaling has more terms than the simple scaling and depends on the modified moisture flux in the base climate, the only changes it requires are in surface-air quantities. The assumptions made in deriving the extended scaling amount to assuming that the mean moisture flux scales with the specific humidity and that the transient-eddy moisture flux scales with the horizontal specific humidity gradient. By contrast, the simple scaling [(2)] assumes that the total moisture flux divergence scales with the specific humidity and that changes in relative humidity are negligible.

\section{b. Application of extended scaling}

Unlike the simple scaling, which suggests that all land becomes wetter under climate warming (Fig. 1b), the extended scaling gives regions of both moistening and drying over land (Fig. 1c). In the zonal mean over land, the extended scaling clearly improves the agreement with the simulated changes in $P-E$ (Fig. 3b): the

\footnotetext{
${ }^{3}$ Boos (2012) assumed that the moisture flux scaled with column water vapor rather than surface-air specific humidity, and he found that meridional variations in the zonal-mean relationship between changes in temperature and column water had little effect on changes in $P-E$. We have investigated replacing surface-air specific humidity with column water vapor in (6) and found that it gives similar results to those presented here (Byrne 2015). We choose to use surface-air specific humidity here because the only changes needed to evaluate the resulting scaling are in surface-air quantities.
}

magnitude of the moistening at many latitudes is better captured, including over the Northern Hemisphere midlatitudes, as is the drying in the Southern Hemisphere extratropics. The extended scaling does not give as much moistening of the tropics as the simple scaling but it still overestimates the $P-E$ response substantially in this region, primarily because of mean circulation changes that are not accounted for in the extended scaling (as discussed in section 5). Globalmean changes in land $P-E$ (equivalent to changes in global-mean runoff) are much better estimated by the extended scaling than by the simple scaling, although neither the simple or extended scalings capture the intermodel scatter (Fig. 4). The multimodel mean of the global-mean change in land $P-E$ is $2.7 \% \mathrm{~K}^{-1}$, as compared to estimates of $4.2 \% \mathrm{~K}^{-1}$ from the extended scaling and $9.2 \% \mathrm{~K}^{-1}$ from the simple scaling. The remaining discrepancy between the simulated globalmean runoff changes and the extended scaling may be overestimated here because the transient-eddy moisture fluxes in the base climate are evaluated using daily-mean wind and specific humidity data, which likely leads to an underestimate of the flux-gradient terms in the extended scaling (cf. Seager and Henderson 2013). The discrepancy is also much reduced if the specific humidity form of the extended scaling [(6)] is used. ${ }^{4}$

The extended scaling partially captures interesting features of the simulated response regionally over land, such as drying over North America and the southern part of South America, and the broad drying of southern

\footnotetext{
${ }^{4}$ The specific humidity form [(6)] and temperature/relative humidity form [(7)] of the extended scaling give changes in zonalmean $P-E$ that are generally similar (Fig. S2), but there is a difference between the two forms over ocean at high northern latitudes (Fig. S2a), and the specific humidity form is more negative at many extratropical latitudes over land (Fig. S2b). The changes in $P-E$ from the specific humidity form of the extended scaling also exhibit more finescale structure for reasons that remain unclear. The different forms of the extended scaling do not give identical changes because it is not possible to precisely reproduce the simulated specific humidity using monthly-mean temperature and relative humidity due to the nonlinearity of the ClausiusClapeyron relation. We focus on the temperature/relative humidity form of the extended scaling so that direct comparisons to the simple scaling of Held and Soden (2006) can be made.
} 
a

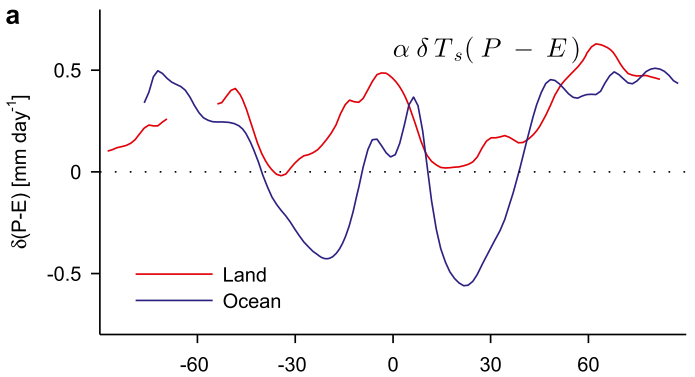

C

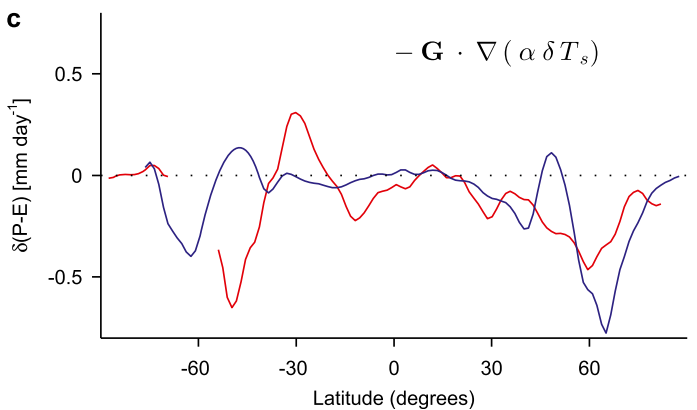

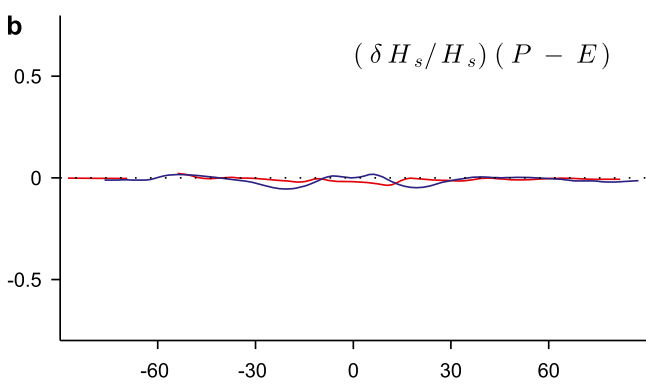

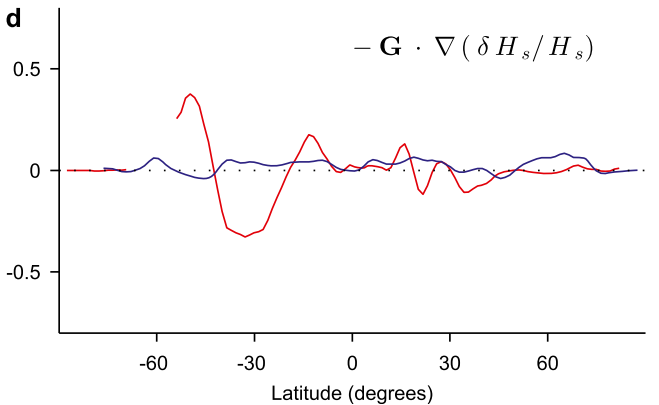

FIG. 5. The various terms in the extended scaling for $P-E$ over land (red) and ocean (blue) in the multimodel and zonal mean. The terms are defined by Eq. (7). Shown are changes in $P-E$ due to (a) the local temperature change (the simple scaling), (b) the local relative humidity change, (c) the gradient of changes in temperature, and (d) the gradient of fractional changes in relative humidity.

Europe and central Asia. Not all features of the simulated changes in $P-E$ are captured because circulation changes are not accounted for, and the extended scaling overestimates the drying and moistening signals in various regions. Nevertheless the extended scaling represents a step toward understanding projections of regional water cycle changes over land. The additional terms in the extended scaling tend to dry the land relative to the simpler scaling, and the physical mechanism behind this drying is discussed in the next section.

Over ocean, the simple and extended scalings are much more similar (Figs. 2b,c). In the zonal mean over ocean, the additional terms in the extended scaling can be seen to be negligible at low latitudes but are more important at high latitudes (Fig. 3a).

\section{Physical interpretation}

We next assess the contributions of the individual terms in the extended scaling, and we describe the mechanism by which gradients of changes in temperature and fractional changes in relative humidity under global warming affect the $P-E$ response over land.

\section{a. Contributions to the extended scaling}

The four components of the extended scaling [(7)] are shown in the zonal mean for land and ocean in Fig. 5. The first term is the simple scaling, which gives moistening at almost all latitudes over land and the familiar "wet-get-wetter, dry-get-drier" pattern over ocean (Fig. 5a). The second term arises from local changes in relative humidity and is negligible at all latitudes over both land and ocean (Fig. 5b). This may seem surprising for land given that land relative humidity decreases substantially as the climate warms, but the change in relative humidity is multiplied by $P-E$ in the second term of the extended scaling [(7)], and the regions and times of year for which the decreases in relative humidity are large coincide with the regions and times when climatological $P-E$ is small, such that the impact of local relative humidity decreases on changes in $P-E$ is small.

The remaining two terms in the extended scaling are dot products of the modified moisture flux in the base climate with gradients of changes in temperature (Fig. 5c) and fractional changes in relative humidity (Fig. 5d), respectively. Over ocean, the term involving the gradient of fractional changes in relative humidity is negligible, and the temperature gradient term is important only at higher latitudes. However, both gradient terms have substantial magnitudes over land.

The gradient term involving relative humidity tends to offset the temperature gradient term to some extent over land (cf. Figs. 5c and 5d), which is not surprising given that changes in temperature and relative humidity over land are strongly anticorrelated (Byrne and 

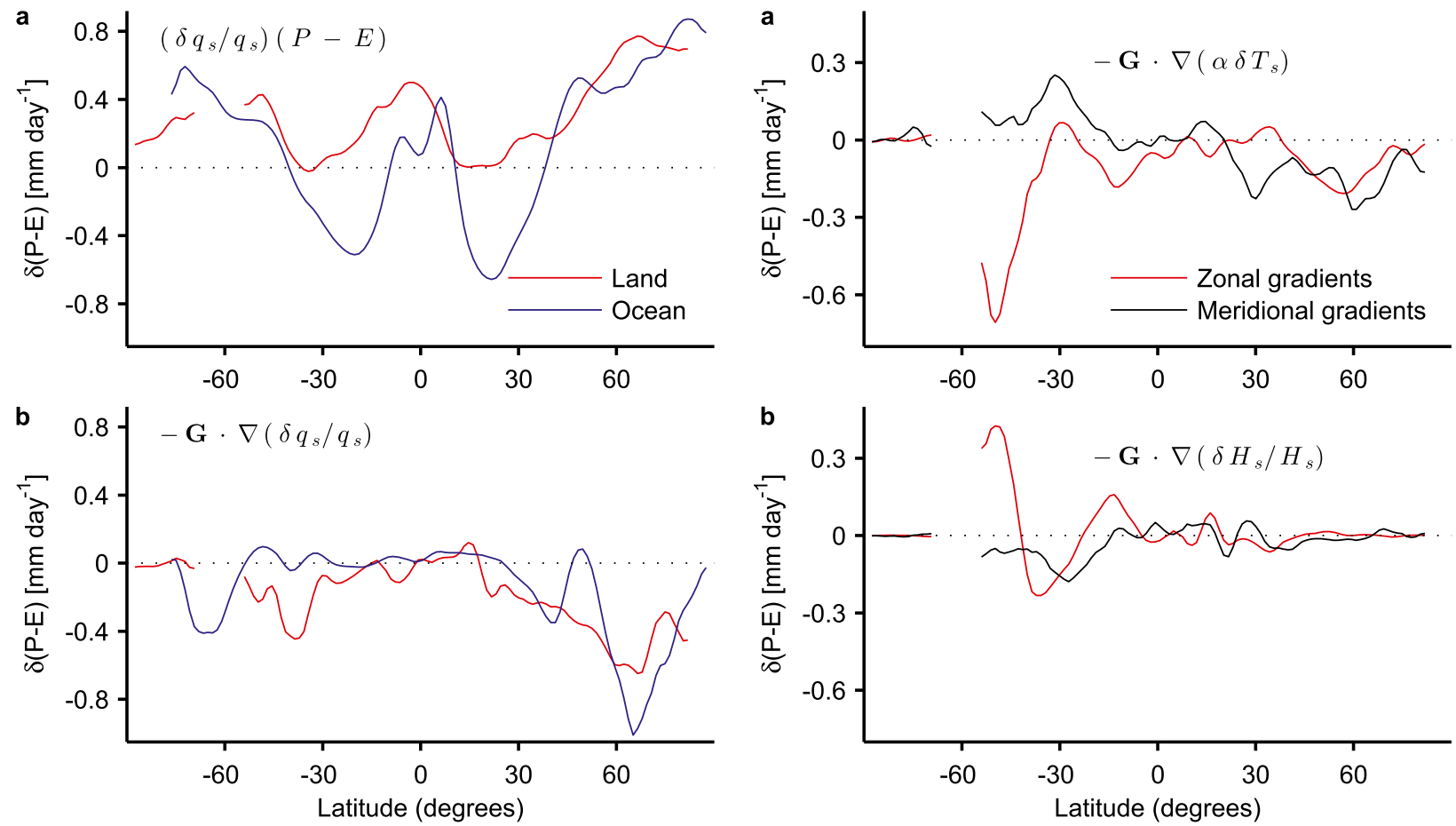

FIG. 6. The contributions to the specific humidity formulation (6) of the extended scaling for $P-E$ over land (red) and ocean (blue). The multimodel and zonal means are plotted. Shown are changes in $P-E$ due to (a) local changes in specific humidity and (b) the gradient of fractional changes in specific humidity.

O'Gorman 2013b). This anticorrelation arises for two reasons. First, decreases in land relative humidity lead to a greater land warming owing to dynamical constraints (Byrne and O'Gorman 2013a,b). Second, greater land warming leads to decreases in land relative humidity for a given change in ocean specific humidity (Rowell and Jones 2006; Simmons et al. 2010; O'Gorman and Muller 2010).

To assess the net contribution of these two gradient terms to changes in $P-E$ over land, we use the specific humidity form of the extended scaling [(6)], which does not require approximations related to the relative humidity or changes in saturation specific humidity. The contribution from local specific humidity changes, $\left(\delta q_{s} / q_{s}\right)(P-E)$, is very similar to the simple scaling although it does include a small correction due to local relative humidity changes (Fig. 6a). The term involving the gradient of fractional changes in specific humidity, $-\mathbf{G} \cdot \boldsymbol{\nabla}\left(\delta q_{s} / q_{s}\right)$, includes the effects of both gradients in the change in temperature and the fractional change in relative humidity, and it gives a drying tendency at almost all latitudes over land and at high latitudes over ocean (Fig. 6b). Thus, despite the partial offsetting of the temperature gradient term by the relative humidity

FIG. 7. The zonal (red) and meridional (black) components of the (a) temperature gradient and (b) relative humidity gradient terms in the extended scaling. Results are shown in the multimodel and zonal mean over land.

gradient term over land, the net effect is to dry the land substantially in the global mean as the climate warms (see also Fig. 4 for the global mean).

The relative importance of changes in zonal versus meridional gradients is assessed over land in Fig. 7. The zonal component reaches larger values than the meridional component for both the temperature gradient (Fig. 7a) and relative humidity gradient (Fig. 7b) terms, although the meridional component is not negligible in either case. The zonal component leads to drying at almost all latitudes for the temperature gradient term, but it leads to either moistening or drying depending on latitude for the relative humidity gradient term. Over ocean, it is the meridional gradients of temperature change that lead to the overall drying tendency of the gradient terms at high latitudes (not shown).

\section{b. Drying mechanisms}

We next seek to understand why the temperature gradient term in the extended scaling tends to give decreases in $P-E$ over land.

The meridional temperature gradient term may be written as $-G_{y} \partial_{y}\left(\alpha \delta T_{s}\right)$ where $y$ is meridional distance and $G_{y}$ is the meridional component of the modified moisture flux G. This term gives a drying in the Northern 

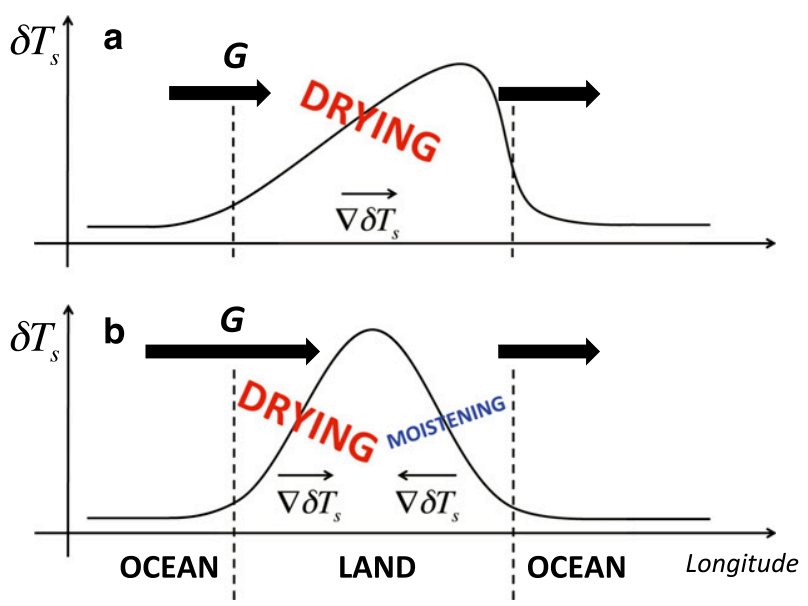

FIG. 8. Schematic diagrams of two mechanisms related to the land-ocean warming contrast by which changes in horizontal temperature gradients can dry a continent: (a) the asymmetricwarming mechanism and (b) the enhanced-land-warming mechanism. The heavy black arrows represent the modified moisture flux $\mathbf{G}$ in the base climate, and the curves are idealized profiles of surface-air temperature changes vs longitude.

Hemisphere extratropics (Fig. 7a), which is related to the poleward moisture flux by eddies (leading to $G_{y}>0$ ) and the polar amplification of warming $\left[\partial_{y}\left(\alpha \delta T_{s}\right)>0\right]$ in the Northern Hemisphere extratropics ( $\alpha$ is also larger at the poles than at the equator, which contributes to the drying tendency). Polar amplification is, therefore, an important contributor to changes in $P-E$ over land in the Northern Hemisphere extratropics.

The zonal temperature gradient term may be written as $-G_{x} \partial_{x}\left(\alpha \delta T_{s}\right)$, where $x$ is zonal distance and $G_{x}$ is the zonal component of the modified moisture flux $\mathbf{G}$, and it gives a drying at almost all latitudes (Fig. 7a). We have identified two distinct drying mechanisms involving this term, both of which relate to the land-ocean warming contrast.

\section{1) “ASYMMETRIC WARMING” MECHANISM}

Consider a nondivergent modified moisture flux $\mathbf{G}$ in the base climate and an asymmetric warming profile over the continent, with enhanced warming on the leeward side compared to the windward side (Fig. 8a). Here, for simplicity, we neglect spatial variations in $\alpha$. In this scenario, the gradient vector of the temperature change is in the same direction as the flux over most of the continent, producing a net drying of the land from $-G_{x} \partial_{x}\left(\alpha \delta T_{s}\right)$. To give a drying, this mechanism requires that the temperature change over land is larger on the leeward coastline than on the windward coastline, as might be expected given the land-ocean warming contrast and the more maritime climate on the windward coast. This is the asymmetric-warming drying mechanism.

\section{2) “ENHANCED LAND WARMING” MECHANISM}

For the second drying mechanism, consider an eastward modified moisture flux $\mathbf{G}$ that is convergent over a continent (Fig. 8b), and a temperature-change profile with enhanced warming over land relative to ocean. The precise shape of the warming profile is not important for this mechanism, but rather the fact that there is greater warming in the continental interior than at the coasts. In contrast to the asymmetric-warming mechanism, the warming can be the same at the east and west coastlines, but the modified moisture flux cannot be nondivergent. In this scenario, the gradient vector of the temperature change points to the east over the western side of the continent (in the same direction as the flux), leading to a drying from $-G_{x} \partial_{x}\left(\alpha \delta T_{s}\right)$, and points to the west on the eastern side, leading to a moistening (Fig. 8b). The flux is convergent, and so the magnitude of the flux is larger over the western side of the continent than over the eastern side. Therefore the drying tendency is of a larger magnitude than the moistening tendency, and there is a net drying tendency in the zonal average over the continent. We refer to this as the enhanced-land-warming drying mechanism. A drying is also obtained if the flux is westward, or if it is pointed to the interior at each coastline, so long as it is convergent over the continent. To the extent that the modified moisture flux behaves similarly to the moisture flux, it may be expected to be convergent over continents because of the need for positive net $P-E$ to balance runoff in the base climate.

\section{3) CONTRIBUTIONS OF EACH MECHANISM}

To quantify the relative roles of the asymmetricwarming mechanism compared to the enhanced-landwarming mechanism in the response of land $P-E$, we decompose the zonal temperature gradient term into a sum of contributions due to each mechanism,

$$
\begin{aligned}
-\left\{G_{x} \frac{\partial\left(\alpha \delta T_{s}\right)}{\partial x}\right\}= & \underbrace{-\left\{G_{x}\right\}\left\{\frac{\partial\left(\alpha \delta T_{s}\right)}{\partial x}\right\}}_{\text {asymmetric warming }} \\
& \underbrace{-\left\{G_{x}^{*}\left[\frac{\partial\left(\alpha \delta T_{s}\right)}{\partial x}\right]^{*}\right\}}_{\text {enhanced land warming }},
\end{aligned}
$$

where $\{\cdot\}$ denotes the zonal mean across a continent and $(\cdot)^{*}$ denotes the departure from the zonal mean across the continent. On the right-hand side of (8), the first term corresponds to the asymmetric-warming mechanism, and the second term corresponds to the enhancedland-warming mechanism. If the warming at both coastlines is equal (and neglecting variations in $\alpha$ across the continent), then $\left\{\partial\left(\alpha \delta T_{s}\right) / \partial x\right\}=0$ and the 


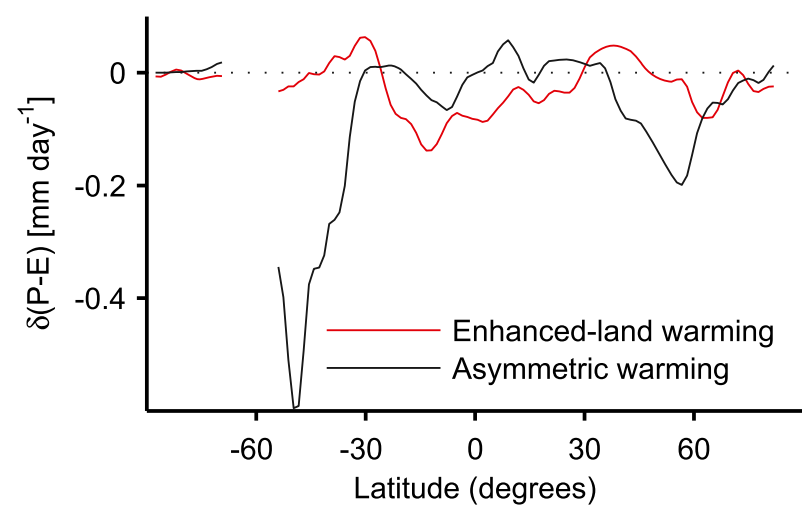

FIG. 9. Contributions to the zonal temperature gradient term in the extended scaling in the multimodel and zonal mean over land. Contributions are shown from east-west asymmetries in surface-air temperature changes (black) and from enhanced-land warming (red), as calculated from (8).

asymmetric warming term is zero. If the warming increases linearly across the continent such that $\left[\partial\left(\alpha \delta T_{s}\right) / \partial x\right]^{*}=0$ or if the zonal component of the modified moisture flux is nondivergent across the continent such that $G_{x}^{*}=0$, then the enhanced-land-warming term is zero.

Interestingly, we find that the asymmetric-warming mechanism dominates in the extratropics but has a smaller magnitude at low latitudes, and the enhancedland-warming mechanism is the more influential mechanism in the tropics (Fig. 9a). The contrasting behavior between low and high latitudes is likely due to stronger mean zonal winds at high latitudes leading to a larger nondivergent flux compared to the divergent flux, as well as greater east-west asymmetry in the surface temperature changes at high latitudes, both of which cause the asymmetric mechanism to be more important at high latitudes.

\section{Role of dynamical changes}

We have highlighted the important role that horizontal gradients of changes in temperature and fractional changes in relative humidity play in the $P-E$ response over land. The extended scaling, which includes these gradient terms, substantially improves the estimates of simulated changes in land $P-E$ relative to the simple scaling. However, the simulated multimodelmean response is not fully captured (Fig. 3b), nor is the intermodel scatter (Fig. 4), indicating that dynamical changes need to be accounted for to fully understand the $P-E$ response over land.

The respective roles of changes in specific humidity versus changes in atmospheric dynamics in influencing $P-E$ are determined using an atmospheric moisture budget decomposition. Following Seager et al. (2010), changes in $P-E$ are written as the sum of a mean thermodynamic component associated with changes in the monthly-mean specific humidity $(\delta \mathrm{MTh})$, a mean dynamic component associated with changes in monthly-mean atmospheric circulations ( $\delta$ MDyn), a transient eddy component ( $\delta$ Eddy), and a nonlinear component associated with changes in both the monthly-mean specific humidity and the monthly-mean circulation $(\delta \mathrm{NL})$. The decomposition is described in appendix A and the definitions of the simple and extended scalings for the mean thermodynamic and transient eddy components are given in appendix B.

Over both land and ocean, the mean thermodynamic component is dominant at many latitudes and is well described by the extended scaling (Figs. 10a and S3a). The transient eddy component over land is also reasonably well described by the extended scaling (Fig. 10b) despite dynamical changes in the eddy field not being included in the extended scaling [the extended scaling is less accurate for the transient eddy component over ocean (Fig. S3b)].

The mean dynamic component is neglected by the extended scaling, but it is important at low latitudes over land (Fig. 10c) and ocean (Fig. S3c). Over land, the mean dynamic component dries the deep tropics and moistens the subtropics (Fig. 10c). Comparison with the contribution of the mean circulation to $P-E$ in the control climate (Fig. S4) suggests that these changes are consistent with a slowdown of the tropical circulation (Vecchi and Soden 2007) in the deep tropics and to a lesser extent in the subtropics. This slowdown is also evident in a map of the mean dynamic component (Fig. S5c). Interestingly, the mean dynamic component at the extratropical edge of the subtropics gives a moistening over land but a drying over ocean (cf. the black and blue lines in Fig. 10c). The moistening over land may seem surprising because the poleward expansion of the Hadley cell with warming (e.g., Lu et al. 2007) is often assumed to give a drying at the edge of the subtropics. However, the contribution of the mean circulation to zonal-mean $P-E$ in the base climate is quite different over land and ocean (Fig. S4) such that a poleward expansion may be expected to give different responses over land and ocean. For example, at $30^{\circ} \mathrm{S}$ a poleward expansion of the mean circulation would give a drying over ocean but a moistening over land (not shown), consistent with the signs of the mean dynamic component at this latitude (Fig. 10c).

The nonlinear component, involving changes in both the specific humidity and wind fields, has a similar spatial structure to the mean dynamic component but a smaller magnitude (Fig. 10d; see also Figs. S3d and S5d). It is shown in appendix A [see Eq. (A6)] that the nonlinear component is approximately related to the mean dynamical component: 

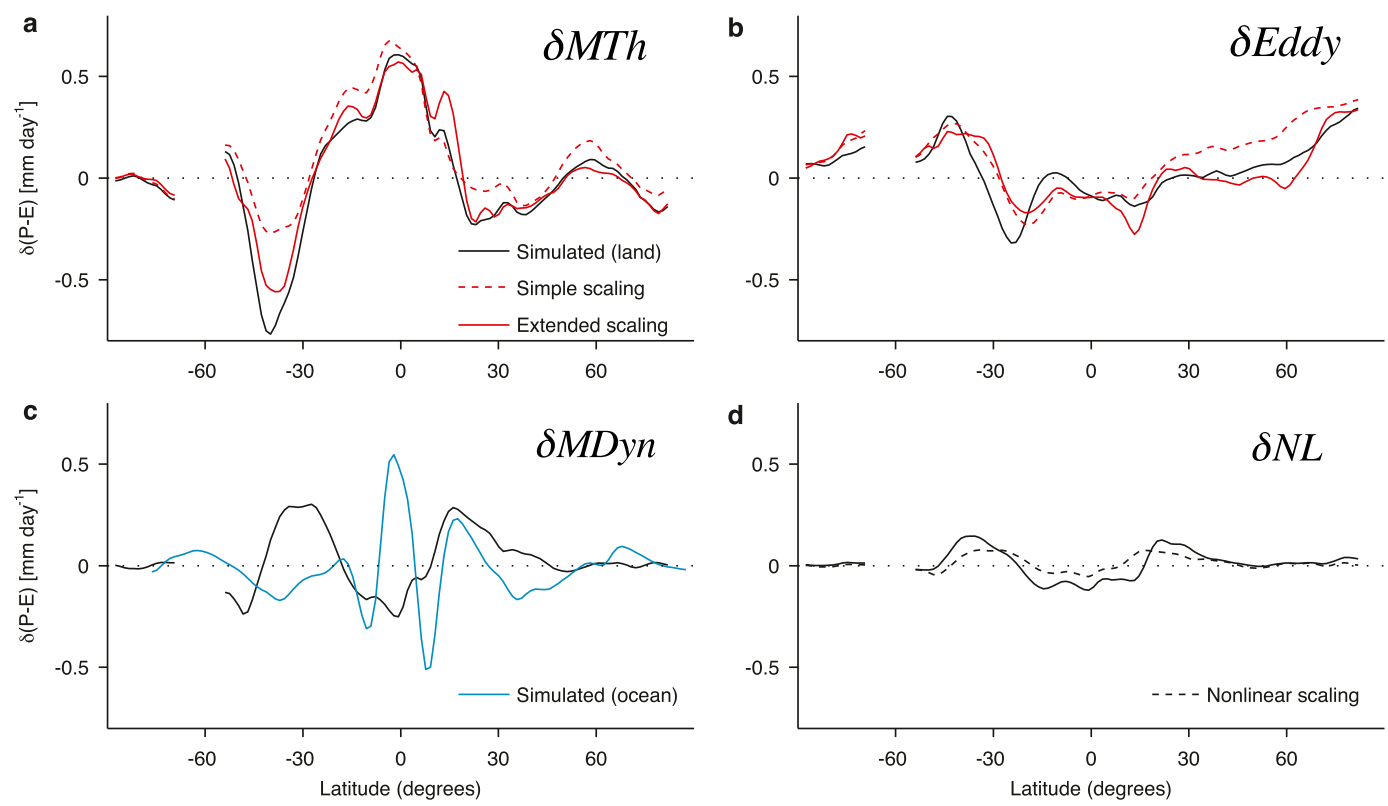

FIG. 10. Contributions to changes in $P-E$ over land from (a) the mean thermodynamic component, (b) the transient eddy component, (c) the mean dynamic component, and (d) the nonlinear component [the various terms are defined by (A5)]. Solid black lines denote the simulated changes, and the red dashed and red solid lines are the estimates from the simple [(B1) and (B2)] and extended [(B3) and (B4)] scalings, respectively. The black dashed line in (d) is the nonlinear scaling (9). The blue line in (c) shows the mean dynamic component over ocean for comparison. Results are shown in the multimodel and zonal mean.

$$
\delta \mathrm{NL} \approx \alpha \delta T_{s} \delta \mathrm{MDyn}
$$

This scaling captures the magnitude and some of the structure of the nonlinear component in the simulations over both land (Fig. 10d) and ocean (Fig. S3d), and it suggests that the nonlinear term tends to amplify the mean dynamic component.

The above analysis shows that the extended scaling captures the mean thermodynamic component and much of the transient-eddy component over land. A full theory for changes in $P-E$ under global warming requires an understanding of not only the effects of changes in the specific humidity field, which the extended scaling captures well, but also an understanding of changes in the atmospheric circulation. The changes in circulation are linked to the changes in horizontal temperature gradients via the thermal wind balance, which means that the dynamic component and the temperature gradient term in the extended scaling are not fully independent.

\section{Conclusions}

We have investigated $P-E$ changes in CMIP5 simulations and found that their magnitude and latitudinal structure are different over land and ocean. Our analysis is based on the moisture budget, but a land-ocean contrast is also evident in the local energetic perspective on precipitation changes (Muller and O'Gorman 2011), and this is worthy of further study. The ocean $P-E$ response on large scales can be understood as an enhancement of climatological $P-E$ resulting from increased atmospheric moisture transport in a warmer climate. However, this "wet-get-wetter, dry-get-drier" scaling does not apply over land, where it substantially overestimates the simulated moistening and does not capture the projected drying in many regions.

Modifying the simple scaling of Held and Soden (2006) by accounting for changes in horizontal temperature gradients and relaxing the assumption of fixed relative humidity, we have derived an extended scaling for $P-E$. The extended scaling includes additional terms that involve the horizontal moisture flux and horizontal gradients of changes in surface-air temperature and fractional changes in surface-air relative humidity. The moisture flux by transient eddies is related to the time-mean specific humidity field using a diffusive approximation, and this leads to a factor of 2 that multiplies its contribution to the gradient terms. The extended scaling also accounts for the effect of local changes in relative humidity, but this turns out to be negligible. The temperature gradient term had previously 
been found to be important in simulated $P-E$ changes between the present day and the LGM (Boos 2012). Here, we find that the extended scaling substantially improves estimates of changes in land $P-E$ globally, in the zonal mean, and regionally. In particular, it gives an improved estimate of the global-mean runoff changes $\left(4.2 \% \mathrm{~K}^{-1}\right.$ versus a simulated value of $\left.2.7 \% \mathrm{~K}^{-1}\right)$ as compared to the simple scaling $\left(9.2 \% \mathrm{~K}^{-1}\right)$, and it captures to some extent the projected drying in parts of southern South America, North America, and Europe. In the zonal mean over land, the extended scaling gives a response of $P-E$ that is more negative than the simple scaling at almost all latitudes, with increases in $P-E$ in the tropics and at high latitudes and smaller decreases at latitudes in between.

The zonal temperature gradient term in the extended scaling gives a drying at almost all latitudes over land, and two distinct drying mechanisms were identified for this term. The first mechanism arises from the east-west asymmetry in the warming across continents and gives a drying to the extent that there is greater warming on the leeward side of the continent (as might be expected given the land-warming contrast and the more continental climate on the leeward side). The second mechanism arises from the enhanced warming over continental interiors and gives a drying assuming there is a convergent modified moisture flux over the continent in the base climate. The first mechanism is dominant in the extratropics, while the second mechanism is more important in the tropics and subtropics. The meridional temperature gradient term also contributes, and polar amplified warming leads to an important drying tendency in the extratropics of the Northern Hemisphere. Gradients of fractional changes in relative humidity oppose the effects of the gradients in warming to some extent but are not large enough to cancel them, and further work is needed to better understand the degree of cancellation of the two terms.

The extended scaling is generally more similar to the simple scaling over ocean than over land, but meridional gradients of temperature change do give a drying tendency over high-latitude oceans. Circulation changes are not included in the extended scaling and are important for changes in $P-E$ over both land and ocean. Interestingly, the mean dynamic component at the extratropical edge of the subtropics gives a drying in the zonal mean over ocean but a moistening in the zonal mean over land. These opposite signed changes are not necessarily inconsistent with a poleward expansion of the Hadley cell because the contribution of the mean circulation to $P-E$ in the base climate has quite different meridional structures over land and ocean.
The extended scaling provides a relatively simple way to understand first-order changes in $P-E$ over land under global warming. The extended scaling is attractive because, like the simple scaling, the only changes it requires are in surface quantities. In fact, if the form given by (6) is used, then the only changes needed are those in the surface-air specific humidity field. A primary merit of the extended scaling is in helping to show why the "wet-gets-wetter, dry-gets-drier" principle does not hold over land, and in showing that the drying relative to the simple scaling is related to robust features such as the land-ocean warming contrast and polar amplification of warming. Of course, not all regional-scale features of the response can be explained with the extended scaling because of circulation changes, particularly at low latitudes.

We have focused here on annual-mean changes in $P-E$ under global warming, but it would also be interesting to use a similar approach to investigate the response of $P-E$ to changes in stomatal conductance, and to examine periods of notable terrestrial drying over the historical period and in paleoclimate records. Mechanisms for seasonal changes have also been suggested (e.g., Wetherald and Manabe 1995; Gregory et al. 1997; Rowell and Jones 2006) and future research could apply the extended scaling to investigate water cycle changes in different seasons.

Acknowledgments. We thank Bill Boos for helpful discussions and two anonymous reviewers for useful comments. We acknowledge the World Climate Research Programme's Working Group on Coupled Modelling, which is responsible for CMIP, and we thank the climate modeling groups for producing and making available their model output. For CMIP, the U.S. Department of Energy's Program for Climate Model Diagnosis and Intercomparison provides coordinating support and led development of software infrastructure in partnership with the Global Organization for Earth System Science Portals. This work was supported in part by the federal, industrial, and foundation sponsors of the MIT Joint Program on the Science and Policy of Global Change. We also acknowledge support from NSF Grant AGS-1148594 and NASA ROSES Grant 09-IDS09-0049.

\section{APPENDIX A}

\section{Atmospheric Moisture Budget Decomposition}

In this appendix we describe the decomposition of the atmospheric moisture budget that is used in section 5 . Our method of decomposition is similar to that of Seager et al. (2010). In the time mean, the tendency of 
the moisture content of the atmosphere can be neglected, and the convergence of the horizontal moisture flux in the atmosphere is balanced by the net water flux into the surface:

$$
P-E=-\nabla \cdot \mathbf{F}=-\nabla \cdot[\overline{\mathbf{u} q}]_{p},
$$

where $\mathbf{u}=(u, v)$ is the horizontal wind vector, $q$ is the specific humidity, $[\cdot]_{p} \equiv(1 / g) \int_{0}^{p_{s}}(\cdot) d p$ represents a mass-weighted, vertical integral over the depth of the atmosphere ( $g$ is the gravitational acceleration, and $p_{s}$ is the surface pressure), and overbars $\overline{(\cdot)}$ denote climatological monthly means. To be consistent with the notation in the main text, $P-E$ and $\mathbf{F}$ are climatological monthly means.

Changes in $P-E$ between two climates are equal to the changes in the moisture flux convergence:

$$
\delta(P-E)=-\nabla \cdot \delta\left([\overline{\mathbf{u} q}]_{p}\right) .
$$

Defining departures from climatological monthly means with primes (e.g., $\mathbf{u}=\overline{\mathbf{u}}+\mathbf{u}^{\prime}$ ), we can decompose $P-E$ into a component due to monthly-mean winds and humidity, and a component due to transient eddies:

$$
\begin{aligned}
P-E & =-\nabla \cdot\left[\overline{\left(\overline{\mathbf{u}}+\mathbf{u}^{\prime}\right)\left(\bar{q}+q^{\prime}\right)}\right]_{p} \\
& =-\nabla \cdot[\overline{\mathbf{u}} \bar{q}]_{p}-\nabla \cdot\left[\overline{\bar{u}^{\prime} q^{\prime}}\right]_{p} .
\end{aligned}
$$

For a change in climate we can write

$$
\delta(P-E)=-\nabla \cdot \delta\left([\overline{\mathbf{u}} \bar{q}]_{p}\right)-\nabla \cdot \delta\left(\left[\overline{\overline{\mathbf{u}}^{\prime} q^{\prime}}\right]_{p}\right) .
$$

Following Seager et al. (2010), we further divide the mean component of $\delta(P-E)$ into a mean thermodynamic part, $\delta \mathrm{MTh}$, involving changes in mean specific humidity with fixed mean winds, and a mean dynamic part, $\delta \mathrm{MDyn}$, involving changes in mean winds with a fixed humidity field. ${ }^{\mathrm{A}}$ The moisture convergence by transient eddies, $\delta$ Eddy, is a covariance term and so it is not straightforward to decompose it into thermodynamic and dynamic components, although it could in principle be decomposed using the diffusive formulation discussed in section 3a. There is also a nonlinear term, $\delta \mathrm{NL}$, involving the product of changes in the mean wind and mean humidity fields. The final decomposition is

\footnotetext{
${ }^{\text {A1 }}$ The decomposition of Seager et al. (2010) results in a term related to moisture advection down surface pressure gradients [see Eqs. (1) and (3) in that paper]. However, this surface-pressure term does not appear in our decomposition [(A5)] because we have chosen to take divergences of the vertically integrated changes in moisture fluxes rather than taking the vertical integrals of the moisture flux divergences as in Seager et al. (2010).
}

$$
\begin{aligned}
& \delta(P-E)= \underbrace{-\nabla \cdot[\overline{\mathbf{u}} \delta(\bar{q})]_{p}}_{\delta \mathrm{MTh}} \underbrace{-\nabla \cdot[\delta(\overline{\mathbf{u}}) \bar{q}]_{p}}_{\delta \mathrm{MDyn}} \\
& \underbrace{-\nabla \cdot \delta\left(\left[\overline{\mathbf{u}^{\prime} q^{\prime}}\right]_{p}\right)}_{\delta \mathrm{Eddy}} \underbrace{-\nabla \cdot[\delta(\overline{\mathbf{u}}) \delta(\bar{q})]_{p}}_{\delta \mathrm{NL}} .
\end{aligned}
$$

Seager et al. (2010) found the nonlinear term was negligible. We find that the nonlinear term is a substantial contributor to the $P-E$ changes, particularly over land, and this is likely because we consider a larger change in climate than Seager et al. (2010) (we use a scenario with higher emissions and a later time period for the future climate). Assuming that the specific humidity increases with warming at a rate of $\alpha$ and neglecting gradients of changes in temperature and gradients of $\alpha$ for simplicity, the nonlinear component may be related to the mean dynamic component,

$\delta \mathrm{NL} \equiv-\nabla \cdot[\delta(\overline{\mathbf{u}}) \delta(\bar{q})]_{p} \approx-\alpha \delta T_{s} \nabla \cdot[\delta(\overline{\mathbf{u}}) \bar{q}]_{p}$,

which gives the result (9).

To calculate the mean thermodynamic, dynamic, and nonlinear components we use monthly-mean winds and specific humidities. The transient eddy term is calculated explicitly using daily data. The vertical integral of a given field through the atmosphere is evaluated by linearly interpolating to estimate the field's values at the midpoints between the archived pressure levels, multiplying by the pressure difference between the levels, and then summing over all pressure levels (we use the surface-air level as an extra level for the vertical integral). The divergences are calculated by taking derivatives of spline interpolations of the given field in the zonal and meridional directions. The calculation of $\delta(P-E)$ from the moisture budget [right side of (A5)] matches the simulated $\delta(P-E)$ [left side of (A5)] to a very good approximation over oceans. Over land, the budget is somewhat less accurate, which is likely due to difficulties in calculating divergences in regions of topography, and also due to our discretization method being different to that of each individual model, as noted by Seager et al. (2010).

\section{APPENDIX B}

\section{Simple and Extended Scalings for the Mean Thermodynamic and Transient Eddy Components of $\delta(P-E)$}

The simple (2) and extended (7) scalings can be applied separately to the mean thermodynamic and transient eddy components of $\delta(P-E)$ as defined by (A5).

The simple scalings for the mean thermodynamic and transient eddy components are 


$$
\begin{aligned}
& (\delta \mathrm{MTh})_{\text {simple }}=-\alpha \delta T_{s} \boldsymbol{\nabla} \cdot \mathbf{F}_{\text {mean }}=\alpha \delta T_{s}(P-E)_{\text {mean }} \\
& (\delta \mathrm{Eddy})_{\text {simple }}=-\alpha \delta T_{s} \boldsymbol{\nabla} \cdot \mathbf{F}_{\text {eddy }}=\alpha \delta T_{s}(P-E)_{\text {eddy }}
\end{aligned}
$$

where $\mathbf{F}_{\text {mean }}$ and $\mathbf{F}_{\text {eddy }}$ are the vertically integrated horizontal moisture fluxes associated with the climatological monthly-mean circulation and with transient eddies, respectively, and $(P-E)_{\text {mean }}=-\nabla \cdot \mathbf{F}_{\text {mean }}$ and $(P-E)_{\text {eddy }}=-\nabla \cdot \mathbf{F}_{\text {eddy }}$ are the convergences of these fluxes.

The extended scaling for the mean thermodynamic component is

$$
\begin{aligned}
(\delta \mathrm{MTh})_{\text {extended }}= & \left(\alpha \delta T_{s}+\delta H_{s} / H_{s}\right)(P-E)_{\text {mean }} \\
& -\mathbf{F}_{\text {mean }} \cdot \nabla\left(\alpha \delta T_{s}\right)-\mathbf{F}_{\text {mean }} \cdot \nabla\left(\delta H_{s} / H_{s}\right) .
\end{aligned}
$$

Following the derivation of (5), which assumes the transient-eddy moisture flux acts diffusively, the extended scaling for the transient-eddy component is

$$
\begin{aligned}
(\delta \text { Eddy })_{\text {extended }}= & \left(\alpha \delta T_{s}+\delta H_{s} / H_{s}\right)(P-E)_{\text {eddy }} \\
& -2 \mathbf{F}_{\text {eddy }} \cdot \nabla\left(\alpha \delta T_{s}\right)-2 \mathbf{F}_{\text {eddy }} \cdot \nabla\left(\delta H_{s} / H_{s}\right) .
\end{aligned}
$$

\section{REFERENCES}

Alkama, R., L. Marchand, A. Ribes, and B. Decharme, 2013: Detection of global runoff changes: Results from observations and CMIP5 experiments. Hydrol. Earth Syst. Sci., 17, 29672979, doi:10.5194/hess-17-2967-2013.

Boos, W. R., 2012: Thermodynamic scaling of the hydrological cycle of the Last Glacial Maximum. J. Climate, 25, 992-1006, doi:10.1175/JCLI-D-11-00010.1.

Byrne, M. P., 2015: Land-ocean contrasts under climate change. Ph.D. thesis, Massachusetts Institute of Technology, $163 \mathrm{pp}$.

_- and P. A. O'Gorman, 2013a: Land-ocean warming contrast over a wide range of climates: Convective quasi-equilibrium theory and idealized simulations. J. Climate, 26, 4000-4016, doi:10.1175/JCLI-D-12-00262.1.

$\longrightarrow$, and _ 2013b: Link between land-ocean warming contrast and surface relative humidities in simulations with coupled climate models. Geophys. Res. Lett., 40, 5223-5227, doi:10.1002/grl.50971.

Cao, L., G. Bala, K. Caldeira, R. Nemani, and G. Ban-Weiss, 2010: Importance of carbon dioxide physiological forcing to future climate change. Proc. Natl. Acad. Sci. USA, 107, 9513-9518, doi:10.1073/pnas.0913000107.

Chadwick, R., I. Boutle, and G. Martin, 2013: Spatial patterns of precipitation change in CMIP5: Why the rich do not get richer in the tropics. J. Climate, 26, 3803-3822, doi:10.1175/JCLI-D-12-00543.1.

Chou, C., and J. D. Neelin, 2004: Mechanisms of global warming impacts on regional tropical precipitation. J. Climate, 17, 2688-2701, doi:10.1175/1520-0442(2004)017<2688:MOGWIO>2.0.CO;2.
,-- C.-A. Chen, and J.-Y. Tu, 2009: Evaluating the "richget-richer" mechanism in tropical precipitation change under global warming. J. Climate, 22, 1982-2005, doi:10.1175/ 2008JCLI2471.1.

Collins, M., and Coauthors, 2013: Long-term climate change: Projections, commitments and irreversibility. Climate Change 2013: The Physical Science Basis, T. F. Stocker et al., Eds., Cambridge University Press, 1029-1136.

Dai, A., T. Qian, K. E. Trenberth, and J. D. Milliman, 2009: Changes in continental freshwater discharge from 1948 to 2004. J. Climate, 22, 2773-2792, doi:10.1175/2008JCLI2592.1.

Durack, P. J., S. E. Wijffels, and R. J. Matear, 2012: Ocean salinities reveal strong global water cycle intensification during 1950 to 2000. Science, 336, 455-458, doi:10.1126/science.1212222.

Fu, Q., and S. Feng, 2014: Responses of terrestrial aridity to global warming. J. Geophys. Res. Atmos., 119, 7863-7875, doi:10.1002/ 2014JD021608.

Gregory, J. M., J. F. B. Mitchell, and A. J. Brady, 1997: Summer drought in northern midlatitudes in a time-dependent $\mathrm{CO}_{2}$ climate experiment. J. Climate, 10, 662-686, doi:10.1175/ 1520-0442(1997)010<0662:SDINMI >2.0.CO;2.

Greve, P., B. Orlowsky, B. Mueller, J. Sheffield, M. Reichstein, and S. I. Seneviratne, 2014: Global assessment of trends in wetting and drying over land. Nat. Geosci., 7, 716-721, doi:10.1038/ ngeo2247.

Held, I. M., and B. J. Soden, 2006: Robust responses of the hydrological cycle to global warming. J. Climate, 19, 5686-5699, doi:10.1175/JCLI3990.1.

Holland, M. M., and C. M. Bitz, 2003: Polar amplification of climate change in coupled models. Climate Dyn., 21, 221-232, doi:10.1007/s00382-003-0332-6.

Huang, P., S.-P. Xie, K. Hu, G. Huang, and R. Huang, 2013: Patterns of the seasonal response of tropical rainfall to global warming. Nat. Geosci., 6, 357-361, doi:10.1038/ngeo1792.

IPCC, 2014: Climate Change 2014: Impacts, Adaptation, and Vulnerability. Part A: Global and Sectoral Aspects. Cambridge University Press, 1132 pp. [Available online at http://www.ipcc.ch/ pdf/assessment-report/ar5/wg2/WGIIAR5-PartA_FINAL.pdf.]

Joshi, M. M., J. M. Gregory, M. J. Webb, D. M. H. Sexton, and T. C. Johns, 2008: Mechanisms for the land/sea warming contrast exhibited by simulations of climate change. Climate Dyn., 30, 455-465, doi:10.1007/s00382-007-0306-1.

Laîné, A., H. Nakamura, K. Nishii, and T. Miyasaka, 2014: A diagnostic study of future evaporation changes projected in CMIP5 climate models. Climate Dyn., 42, 2745-2761, doi:10.1007/s00382-014-2087-7.

Lu, J., G. A. Vecchi, and T. Reichler, 2007: Expansion of the Hadley cell under global warming. Geophys. Res. Lett., 34, L06805, doi:10.1029/2006GL028443.

Mitchell, J. F. B., C. A. Wilson, and W. M. Cunnington, 1987: On $\mathrm{CO}_{2}$ climate sensitivity and model dependence of results. Quart. J. Roy. Meteor. Soc., 113, 293-322, doi:10.1002/qj.49711347517.

Muller, C. J., and P. A. O'Gorman, 2011: An energetic perspective on the regional response of precipitation to climate change. Nat. Climate Change, 1, 266-271, doi:10.1038/nclimate1169.

O'Gorman, P. A., and T. Schneider, 2006: Stochastic models for the kinematics of moisture transport and condensation in homogeneous turbulent flows. J. Atmos. Sci., 63, 2992-3005, doi:10.1175/JAS3794.1.

- and C. J. Muller, 2010: How closely do changes in surface and column water vapor follow Clausius-Clapeyron scaling in climate change simulations? Environ. Res. Lett., 5, 025207, doi:10.1088/1748-9326/5/2/025207. 
Roderick, M. L., F. Sun, W. H. Lim, and G. D. Farquhar, 2014: A general framework for understanding the response of the water cycle to global warming over land and ocean. Hydrol. Earth Syst. Sci., 18, 1575-1589, doi:10.5194/hess-18-1575-2014.

Rowell, D. P., and R. G. Jones, 2006: Causes and uncertainty of future summer drying over Europe. Climate Dyn., 27, 281-299, doi:10.1007/s00382-006-0125-9.

Scheff, J., and D. M. W. Frierson, 2012: Twenty-first-century multimodel subtropical precipitation declines are mostly midlatitude shifts. J. Climate, 25, 4330-4347, doi:10.1175/ JCLI-D-11-00393.1.

$\longrightarrow$, and — 2015: Terrestrial aridity and its response to greenhouse warming across CMIP5 climate models. J. Climate, 28, 5583-5600, doi:10.1175/JCLI-D-14-00480.1.

Seager, R., and G. A. Vecchi, 2010: Greenhouse warming and the 21st century hydroclimate of southwestern North America. Proc. Natl. Acad. Sci. USA, 107, 21 277-21 282, doi:10.1073/ pnas.0910856107.

, and N. Henderson, 2013: Diagnostic computation of moisture budgets in the ERA-Interim reanalysis with reference to analysis of CMIP-archived atmospheric model data. J. Climate, 26, 7876-7901, doi:10.1175/JCLI-D-13-00018.1.

, N. Naik, and G. A. Vecchi, 2010: Thermodynamic and dynamic mechanisms for large-scale changes in the hydrological cycle in response to global warming. J. Climate, 23, 4651-4668, doi:10.1175/2010JCLI3655.1.

, H. Liu, N. Henderson, I. Simpson, C. Kelley, T. Shaw, Y. Kushnir, and M. Ting, 2014a: Causes of increasing aridification of the Mediterranean region in response to rising greenhouse gases. J. Climate, 27, 4655-4676, doi:10.1175/ JCLI-D-13-00446.1.
_ , and Coauthors, 2014b: Dynamical and thermodynamical causes of large-scale changes in the hydrological cycle over North America in response to global warming. J. Climate, 27, 7921-7948, doi:10.1175/JCLI-D-14-00153.1.

Simmons, A. J., K. M. Willett, P. D. Jones, P. W. Thorne, and D. P. Dee, 2010: Low-frequency variations in surface atmospheric humidity, temperature, and precipitation: Inferences from reanalyses and monthly gridded observational data sets. J. Geophys. Res., 115, D01110, doi:10.1029/2009JD012442.

Sutton, R. T., B. Dong, and J. M. Gregory, 2007: Land/sea warming ratio in response to climate change: IPCC AR4 model results and comparison with observations. Geophys. Res. Lett., 34, L02701, doi:10.1029/2006GL028164.

Taylor, K. E., R. J. Stouffer, and G. A. Meehl, 2012: An overview of CMIP5 and the experiment design. Bull. Amer. Meteor. Soc., 93, 485-498, doi:10.1175/BAMS-D-11-00094.1.

Vallis, G. K., P. Zurita-Gotor, C. Cairns, and J. Kidston, 2015: Response of the large-scale structure of the atmosphere to global warming. Quart. J. Roy. Meteor. Soc., 141, 1479-1501, doi:10.1002/qj.2456.

Vecchi, G. A., and B. J. Soden, 2007: Global warming and the weakening of the tropical circulation. J. Climate, 20, 43164340, doi:10.1175/JCLI4258.1.

Wetherald, R. T., and S. Manabe, 1995: The mechanisms of summer dryness induced by greenhouse warming. J. Climate, 8, 3096-3108, doi:10.1175/1520-0442(1995)008<3096: TMOSDI $>2.0 . \mathrm{CO} ; 2$.

Xie, S.-P., C. Deser, G. A. Vecchi, J. Ma, H. Teng, and A. T. Wittenberg, 2010: Global warming pattern formation: Sea surface temperature and rainfall. J. Climate, 23, 966-986, doi:10.1175/2009JCLI3329.1. 